\title{
Left coronary artery anatomy in patients with bicuspid aortic valves ${ }^{1}$
}

\author{
ALLEN D. JOHNSON, JOHN H. DETWILER, AND CHARLES B. HIGGINS
}

From the Division of Cardiology, Department of Medicine, and the Department of Radiology, University of California, San Diego School of Medicine, La folla; University of California San Diego Medical Center, San Diego, and San Diego Veterans Administration Hospital, La folla, California, USA

SUMMARY The anatomy of the proximal left coronary artery in 33 adult patients with bicuspid aortic valves was compared with that in 33 adult patients with aortic valve disease of other aetiologies and with that in 50 adult control patients with no valve or congenital heart disease. Patients with bicuspid aortic valves had a higher incidence of immediate bifurcation of the left main coronary artery, of left main coronary length less than $10 \mathrm{~mm}$, and of left coronary artery dominance. The mean length of the left main coronary artery was significantly less in the patients with bicuspid aortic valves. These variations from the usual coronary artery anatomy may be part of the developmental abnormalities responsible for bicuspid aortic valves, and require evaluation and consideration when considering angiography and valve replacement in patients with aortic stenosis.

Aortic stenosis occurring in the setting of a congenitally abnormal aortic valve has been associated with several other congenital abnormalities, including coarctation of the aorta, hypoplastic left heart syndrome, and reversal of dominance of the coronary arterial system (Reifenstein et al., 1947; Becker et al., 1970; Simon and Reis, 1971; Rosenquist, 1974; Higgins and Wexler, 1975). In our experience with coronary angiography in adult patients with apparent bicuspid aortic valve disease, we have frequently encountered patients with either a very short left main coronary artery or immediate bifurcation of the left anterior descending and left circumflex coronary arteries. We, therefore, reviewed our angiographic and surgical data regarding the origin and length of the left main coronary artery and structure of the aortic valve in patients with aortic valve disease. The coronary artery anatomy of patients found to have bicuspid aortic valves was compared with that in patients with aortic valve disease of other aetiologies, and with that in a control group of patients who had no clinical or haemodynamic evidence of valvular or congenital heart disease.

\footnotetext{
:Supported in part by a NIH research grant and a training grant awarded by the National Heart, Lung and Blood Institute.
}

Received for publication 25 August 1977

\section{Methods}

We reviewed the cardiac catheterisation data, cineangiograms, and coronary angiograms of the most recent 100 consecutive adult patients studied in our institutions who had clinical, haemodynamic, and angiographic evidence of aortic valve disease. In 66 of these patients, the anatomy of the aortic valve could be determined with certainty, and selective coronary angiograms were of adequate quality to evaluate the origin and length of the left main coronary artery. The most recent 50 patients with no clinical or haemodynamic evidence for valvular or congenital heart disease who underwent coronary angiography and cardiac catheterisation served as a control group.

Coronary angiograms were obtained in multiple projections using 6 in Philips caesium iodide image intensifiers and $35 \mathrm{~mm}$ Arriflex cameras. The length of the left main coronary artery was measured in that projection (usually between 10 and 45 degrees right anterior oblique), where the left main coronary artery was judged to be perpendicular to the $x$-ray beam and where the site of bifurcation of the left anterior descending and circumflex coronary arteries could be most objectively identified (Fig. 1). The length of the left main coronary artery was corrected for magnification by comparison with the non-tapered portion of the No. 8F Judkins or Sones catheters $(2.67 \mathrm{~mm}$ outside diameter) used for 


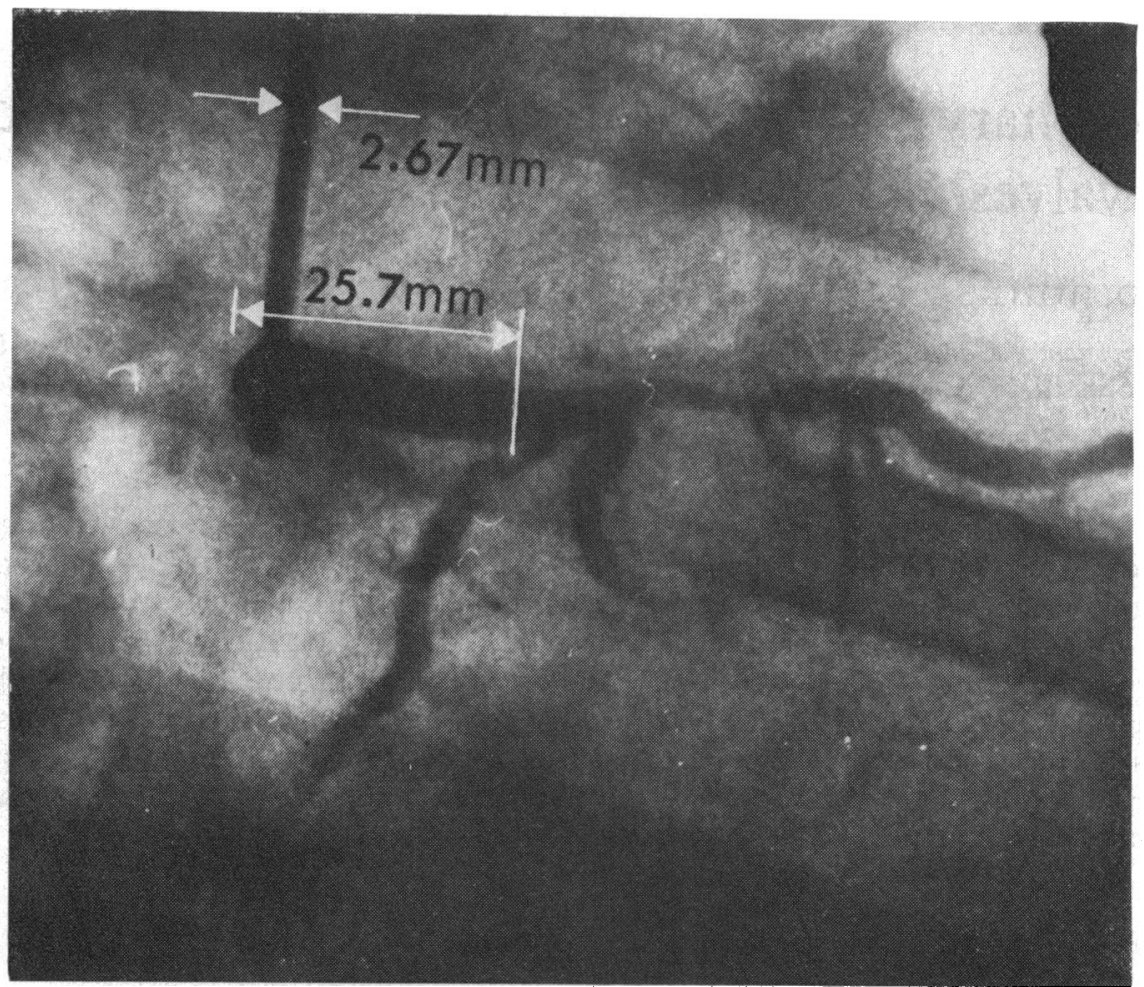

Fig. 1 Method of determining left main coronary length. The left main coronary artery is judged to be perpendicular to the $\mathrm{x}$-ray beam, and the length of the left main coronary artery is taken from its origin to the site of bifurcation of the left anterior descending and circumflex arteries. This measurement is corrected for magnification by comparison with the non-tapered portion of the No. $8 F$ fudkins catheter.

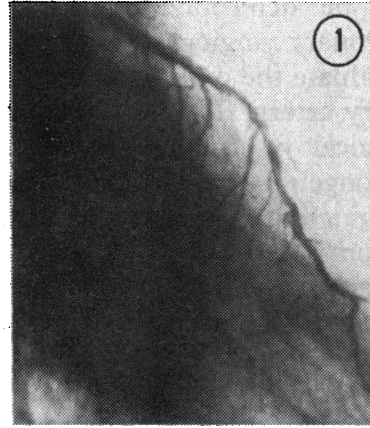

LAD in RAO

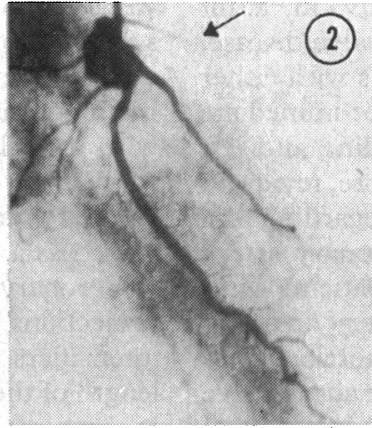

Circumflex in RAO

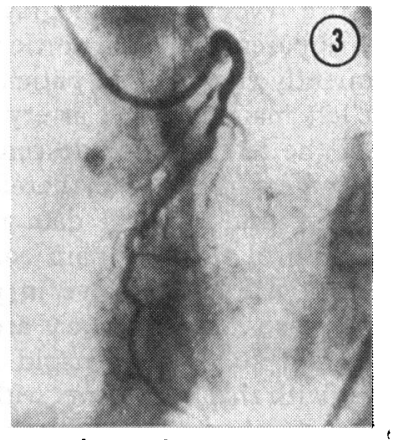

LAD in LAO

Fig. 2 An example of separate origins of the left anterior descending (LAD) and circumflex coronary arteries. Note flash filling of the left anterior descending artery during selective circumflex artery injection in panel 2.

coronary angiography. The left anterior descending and circumflex coronary arteries were judged to have immediate bifurcation if no discrete left main coronary artery could be identified, and/or if selective opacification of either the left anterior descending or circumflex coronary arteries was uniformly obtained (Fig. 2). Left coronary dominance was present when both the posterolateral left 


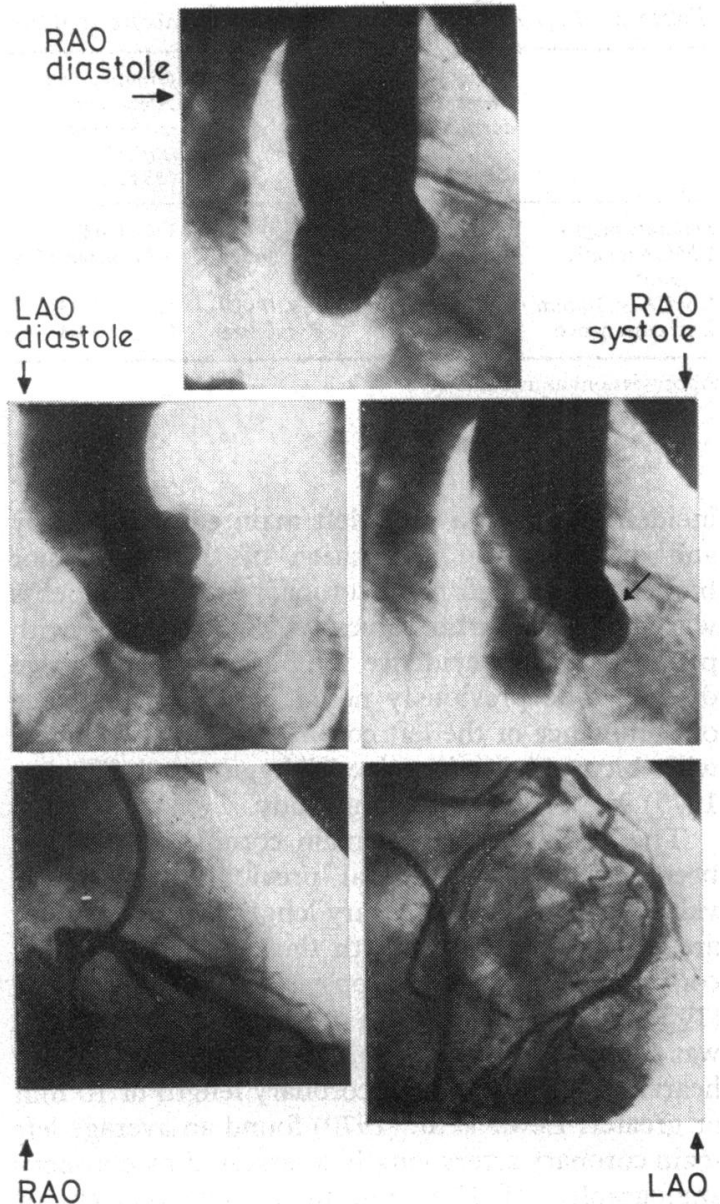

Fig. 3 An example of a patient with a bicuspid aortic valve showing a disproportionately large posterior sinus of Valsalva, an eccentric jet during systole, and an apparent raphe (arrow) separating the cusp associated with the right and left sinuses of Valsalva. In the $R A O$ projection, the coronary angiogram reveals a very short left main coronary artery; the LAO projection shows a left dominant coronary circulation.

ventricular and posterior descending branches arose from the left circumflex coronary artery (Fig. 3). If both of these branches arose from the right coronary artery, right dominance was said to be present. Equal dominance was present if the right coronary artery supplied a posterior descending branch but did not extend beyond the crux.

Transvalvular gradients and valve areas were measured using standard haemodynamic techniques. Supravalve aortic root and left ventricular cineangiograms including the sinuses of Valsalva were exposed biplane through Philips 9 in caesium iodide image intensifiers. The aortic valve was judged to be congenitally abnormal if there was isolated involvement of the aortic valve, and the sinuses of Valsalva appeared unequal on cineangiography (Fig. 3) (Simon and Reis, 1971), or if the valve was described as bicuspid on visual inspection at the time of aortic valve replacement. Aortic valve disease on a non-congenital basis was said to be present if the sinuses of Valsalva appeared normal and were of equal size on cineangiography, and/or the visual evaluation of the valve at the time of surgery revealed three equal cusps. A history of rheumatic heart disease with evidence of mitral valve involvement on physical examination, noninvasive assessment, and cardiac catheterisation, and equal sinuses of Valsalva on angiographic evaluation was considered evidence against the aortic valve being bicuspid if there was no adequate surgical or pathological description of the aortic valve. Otherwise, if no surgical description of the aortic valve was available, and the anatomy of the aortic valve could not be determined with certainty on cineangiograms, the case was not included in this study.

Statistical analyses employed the $\chi^{2}$ technique or analysis of variance.

\section{Results (See Table 1)}

\section{BICUSPID AORTIC VALVE DISEASE}

Thirty-three patients had a congenitally abnormal, bicuspid aortic valve; each of these patients had isolated involvement of the aortic valve. In 24 of these 33 patients, the aortic valve anatomy was confirmed at operation, the supravalvular aortic or left ventricular cineangiograms were diagnostic of a bicuspid aortic valve in 21 of these 24 patients. Nine patients had the diagnosis of bicuspid aortic valve anatomy established by angiography alone. Five of those 9 did not undergo surgery, and the remaining 4 had inadequate surgical documentation of their aortic valve anatomy. In these 33 patients with bicuspid aortic valves, the length of the left

Table 1 Comparison of left main coronary artery anatomy in 3 groups of patients evaluated in this study

\begin{tabular}{llll}
\hline & $\begin{array}{l}\text { Group 1 } \\
\text { BAVD-33 pts }\end{array}$ & $\begin{array}{l}\text { Group 2 } \\
\text { TCAV-33 pts }\end{array}$ & $\begin{array}{l}\text { Group 3 } \\
\text { No AVD-50 pts }\end{array}$ \\
\hline Separate origin & $15 \%(5)$ & $3 \%(1)$ & 0 \\
LMCA length & $0-33$, & $0-37$, & $1-28$, \\
$(m m)$ & mean $5 \cdot 5$ & mean 14.3* & mean $13.0 \star$ \\
LMCA < $10 \mathrm{~mm}$ & $85 \%(28)$ & $36 \%(12)^{\star}$ & $28 \%(15)^{\star}$ \\
Left dominance & $27 \%(9)$ & $12 \%(4)$ & $12 \%(6)$
\end{tabular}

$\star P<0.01$ cf Group 1.

BAVD, patients with bicuspid aortic valves; TCAV = patients with 3 cusped aortic valves; No AVD = patients with no evidence of valvular or congenital heart disease; LMCA = left main coronary artery. 
main coronary artery ranged from 0 to $33 \mathrm{~mm}$, the mean length being $5.5 \mathrm{~mm}$, with only 5 of 33 patients $(15 \%)$ having a left main coronary artery length greater than $10 \mathrm{~mm}$. Six patients had effectively separate origins or immediate bifurcation of the left coronary artery into the left anterior descending and circumflex coronary arteries. There was a 'left dominant' coronary circulation present in 9 of 33 patients $(28 \%)$. Equal dominance of the coronary circulation was noted in 8 of the 33 patients $(24 \%)$. Thus, 52 per cent of patients with bicuspid aortic valves had a non-right dominant coronary circulation. Only 2 patients with a left dominant or equal dominant coronary pattern had a left coronary length greater than $10 \mathrm{~mm} ; 3$ of 16 patients $(19 \%)$ with right coronary dominance had left main coronary artery lengths greater than $10 \mathrm{~mm}$.

\section{THREE CUSPED AORTIC VALVES}

Thirty-three patients had aortic valve anatomy which by angiography alone ( 3 patients) or surgical visual evaluation and angiography (30 patients) revealed 3 equal cusps and sinuses of Valsalva. Of these 33 patients, 18 had evidence of rheumatic involvement of the mitral valve.

In these 33 patients without evidence of congenital deformity of the aortic valve, 1 had immediate bifurcation of the left anterior descending and left circumflex coronary arteries; the length of the left main coronary artery ranged from $0 \mathrm{~mm}$ to $37.0 \mathrm{~mm}$, the mean length being $14.3 \mathrm{~mm}$. Of the 33 patients, $20(61 \%)$ had left main coronary artery lengths greater than $10 \mathrm{~mm}$. Four $(13 \%)$ had a left dominant coronary arterial system, and $4(13 \%)$ had equal coronary dominance.

\section{PATIENTS WITHOUT VALVULAR OR} CONGENITAL HEART DISEASE

In the 50 patients with no evidence of mitral or aortic valve disease, none had separate origins or immediate bifurcation of the left anterior descending coronary and circumflex arteries; the length of the left main coronary artery ranged from $1 \mathrm{~mm}$ to $28.2 \mathrm{~mm}$, and the mean length was $13.0 \mathrm{~mm}$. Thirty-five of 50 patients $(70 \%)$ had left main coronary lengths greater than $10 \mathrm{~mm}$. Six of the 50 patients $(12 \%)$ had left dominant coronary anatomy and $7(14 \%)$ had equal coronary dominance. Statistical comparisons of these features of the coronary anatomy for the three groups of patients are presented in Table 1 and Table 2.

\section{Discussion}

The current study indicates a significantly increased
Table 2 Left coronary artery anatomy in aortic stenosis

\begin{tabular}{|c|c|c|c|}
\hline & \multicolumn{2}{|c|}{$\begin{array}{l}\text { Group } 1 \\
\text { Congenital, bicuspid } \\
\text { aortic valves } \\
\text { (33 patients) }\end{array}$} & \multirow{2}{*}{$\begin{array}{l}\text { Groups } 2 \text { and } 3 \\
\text { Aortic valves } \\
\text { with } 3 \text { equal } \\
\text { leaflets } \\
\text { (83 patients) } \\
\begin{array}{l}1 \%(1 / 83) \\
0-37, \text { mean } 13.5\end{array}\end{array}$} \\
\hline $\begin{array}{l}\text { Separate origin } \\
\text { LMCA length } \\
\text { (mm) }\end{array}$ & $\begin{array}{l}15 \%(5 / 33) \\
0-33, \text { mean } 5 \cdot 5\end{array}$ & $\begin{array}{l}\mathbf{P}<0.01 \\
\mathbf{P}<0.01\end{array}$ & \\
\hline $\begin{array}{l}\text { LMCA }<10 \mathrm{~mm} \\
\text { Left dominance }\end{array}$ & $\begin{array}{l}85 \%(28 / 33) \\
27 \%(9 / 33)\end{array}$ & $\begin{array}{l}\mathbf{P}<0.0001 \\
\mathbf{P}<0.086\end{array}$ & $\begin{array}{l}32 \%(27 / 83) \\
12 \%(10 / 83)\end{array}$ \\
\hline
\end{tabular}

Abbreviations as in Table 1.

incidence of both a short left main coronary artery and of immediate bifurcation of the two major branches of the left main coronary artery in patients with bicuspid aortic valves, when compared with patients without evidence for bicuspid aortic valve disease. The previously noted increased incidence of dominance of the left coronary artery in patients with bicuspid aortic valves (Higgins and Wexler, 1975) was confirmed in our study.

The length of the left main coronary artery has been evaluated in several previous studies; the values for left main coronary length in these studies are in close agreement with those obtained in our control patients. In a necropsy study by Green et al. (1967), the average length of the left main coronary was found to be $11.4 \mathrm{~mm}$, with 62 per cent of the hearts having a left main coronary length of $10 \mathrm{~mm}$ or greater. Lewis et al. (1970) found an average left main coronary artery length, as assessed by coronary angiography, of $12.8 \mathrm{~mm}$ in a control group of patients, 68 per cent of whom had left main coronary artery lengths greater than $10 \mathrm{~mm}$; a group of patients with left bundle-branch block were found to have significantly shorter left main coronary arteries (average length $=4.5 \mathrm{~mm}$ ). None of our patients with bicuspid aortic valve disease had left bundle-branch block. Kronzon et al. (1974) related left main coronary length to the pattern of coronary arterial dominance; the average length of the left main coronary artery in their study was $10.4 \mathrm{~mm}$; however, their patients with a left dominant coronary artery system had an average length for the left main coronary artery of only $3.1 \mathrm{~mm}$. The increased frequency of dominance of the left coronary artery in our patients with bicuspid aortic valves noted in our study and in a previous study by Higgins and Wexler (1975) could partially account for the observed short left main coronary arteries noted in our patients; however, 81 per cent of our patients with right coronary dominance and bicuspid aortic valves also had left main coronary artery lengths less than $10 \mathrm{~mm}$. 
The association between congenitally abnormal bicuspid aortic valves and other congenital abnormalities is well established (Reifenstein et al., 1947; Spencer et al., 1960; Becker et al., 1970; Rosenquist, 1974). Our study suggests that the various anatomical variations of the left coronary artery are occurring on other than a chance basis, and may be related to the developmental abnormalities responsible for bicuspid aortic valve disease.

The occurrence of these variations of left coronary anatomy in the setting of a bicuspid aortic valve has clinical importance. In performing coronary angiography, one should be aware of the increased likelihood of encountering separate origins or immediate bifurcation of the left anterior descending and circumflex coronary arteries, which in our experience causes some difficulty when using preformed left coronary catheters. Likewise, many cardiovascular surgeons use coronary artery perfusion as a means of myocardial protection during aortic valve replacement. Selective perfusion of one of the left coronary branches, with inadequate perfusion of the other branch, might result if the anatomy of the proximal left coronary artery is not properly evaluated (Spencer and Malette, 1968; Furlong et al., 1972; Fox et al., 1973). Coronary perfusion cannulae are normally inserted into the coronary artery between 10 to $15 \mathrm{~mm}$, but can be appropriately modified for use in a shorter left main coronary artery segment. Dominance of the left coronary system, encountered with increased frequency in bicuspid aortic valve disease, compounds the importance of paying particular attention to these variations in coronary anatomy. Accordingly, we suggest that all patients who are being assessed for aortic valve replacement have angiographic documentation of their coronary anatomy, either by selective coronary angiography or by supravalvular aortic root angiography.

\section{References}

Becker, A. E., Becker, M. J., and Edwards, J. E. (1970). Anomalies associated with coarctation of the aorta. Particular reference to infancy. Circulation, 41, 1067-1075.

Fox, C., Davies, M. J., and Webb-Peploe, M. M. (1973). Length of the left main coronary artery. British Heartfournal 35, 796-798.

Furlong, M. B., Jr., Gardner, T. J., Gott, V. L., and Hutchins, G. M. (1972). Myocardial infarction complica:ing coronary perfusion during open heart surgery. Fournal of Thoracic and Cardiovascular Surgery, 63, 185-195.

Green, G. E., Bernstein, S., and Reppart, E. H. (1967). The length of the left main coronary artery. Surgery, 62, 1021-1024.

Higgins, C. B., and Wexler, L. (1975). Reversal of dominance of the coronary arterial system in isolated aortic stenosis and bicuspid aortic valve. Circulation, 52, 292-296.

Kronzon, I., Deutsch, D., and Glassman, E. (1974). Length of the left main coronary artery: its relation to the pattern of coronary arterial distribution. American fournal of Cardiology, 34, 787-789.

Lewis, C. M., Dagenais, G. L., Friesinger, G. C., and Ross, R. S. (1970). Coronary arteriographicappearances in patients with left bundle branch block. Circulation, 41, 299-307.

Reifenstein, G. H., Levine, S. A., and Gross, R. E. (1947). Coarctation of the aorta. A review of 104 autopsied cases of the 'adult type', 2 years of age or older. American Heart Fournal, 33, 146-168.

Rosenquist, G. C. (1974). Congenital mitral valve disease associated with coarctation of the aorta. A spectrum that includes parachute deformity of the mitral valve. Circulation, 49, 985-993.

Simon, A. L., and Reis, R. L. (1971). The angiographic features of bicuspid and unicommissural aortic stenosis. American Fournal of Cardiology, 28, 353-358.

Spencer, F. C., and Malette, W. (1968). Technical considerations of coronary perfusion during aortic valve replacement. Fournal of Cardiovascular Surgery, 9, 562-572.

Spencer, F. C., Neill, C. A., Sank, L., and Bahnson, H. T. (1960). Anatomical variations in 46 patients with congenital aortic stenosis. American Surgeon, 26, 204-216.

Requests for reprints to Dr Allen D. Johnson, San Diego Veterans Administration Hospital, 3350 La Jolla Village Drive, La Jolla, California 92161, USA. 